\title{
Risk factors for postoperative delirium in elderly patients undergoing non- major oral and maxillofacial surgery-a retrospective chart study.
}

\author{
Tomoko Kinugawa ${ }^{\#}$, Yoshinari Morimoto ${ }^{\# *}$, Megumi Hayashi ${ }^{\#}$, Daisuke Takagi, Takatoshi Iida \\ Department of Critical Care Medicine and Dentistry, Graduate School of Dentistry, Kanagawa Dental University, Japan \\ \#These authors contributed equally to this article
}

\begin{abstract}
Background/purpose: Recently, postoperative delirium (POD) has become a major problem in the perioperative management of general anesthesia in elderly patients. In this study, the general anesthesia and perioperative management of elderly patients aged 75 years or older undergoing non-major oral and maxillofacial surgery, and the incidence of POD, were retrospectively investigated, and the risk factors associated with them were determined.

Materials and methods: The study was performed by retrospectively investigating patients' medical records. The items investigated included: patient characteristics, dental diagnosis, concomitant general diseases, including dementia, preoperative laboratory data, anesthesia method (induction and maintenance of anesthesia), changes in blood pressure during anesthesia, duration of anesthesia, duration of surgery, perioperative complications, dose of anesthetics at induction, use of hemodynamic agents, and changes in pre- and postsurgical cognitive function. The Mann-Whitney $U$ test and logistic regression analysis were used for statistical analysis. A significance level of $\mathbf{p}<0.05$ was set for each test. Results and conclusions: The participants were 42 patients ( 15 males and 27 females) with a median age of 81 years. Six patients were preoperatively diagnosed with dementia. The risk factors for POD identified were preoperative diagnosis of dementia, higher age and longer duration of anesthesia. No other factors were significantly related to the risk of POD. Logistic regression analysis demonstrated that a preoperative diagnosis of dementia correlated with postoperative delirium. Six patients developed POD within several hours or 1 day after the end of anesthesia; five of the six patients were diagnosed with dementia preoperatively.
\end{abstract}

Keywords: Dementia, Elderly patient, General anesthesia, Postoperative delirium (POD), Postoperative cognitive dysfunction (POCD).

\section{Introduction}

The perioperative management of general anesthesia in elderly patients often involves various challenges, because complications can arise due to age-related deterioration in organ function. Postoperative delirium (POD) and postoperative cognitive dysfunction (POCD) have become a problem in recent years [1-3]. Review articles have cited advanced age, preoperative use of benzodiazepines, anesthesia duration, use of nitrous oxide, type of surgery, heart disease, alcohol dependency, opioid use, education level, physical status according to the American Society of Anesthesiologists, and preoperative cognitive impairment as risk factors for both POD and POCD $[2,4,5]$. Other factors relating to surgery (anesthesia duration, invasiveness of surgery, hypoxemia, decreased cerebral perfusion due to low blood pressure, high concentration of anesthetics), the hospital environment (prolonged hospitalization, sleep disturbance due to monitor sounds in the intensive care unit, etc.), and postoperative
Accepted on September 22, 2017

factors (inflammatory response, stress-related sleep disturbance, benzodiazepines and other sedatives, and narcotic analgesics used after surgery) have also been implicated $[2,4,5]$. Although there are clearly many contributing factors, few causes have been clearly identified [1-3]. With regard to the relationship between dementia and anesthetic agents, there has been a mix of contradictory reports on the effects of anesthetics on POD and POCD, including basic research, and no consistent trends have been described [6-13]. Although several reports have assessed the risk factors for POD in patients undergoing major head and neck cancer surgery [14-17], the risk factors in patients undergoing non-major oral and maxillofacial surgery have not been identified.

The objective of this study was to investigate the occurrence of systemic complications, particularly cognitive impairment and abnormal behavior characteristic of delirium, in the perioperative period of non-major oral and maxillofacial surgery, and the factors associated with these complications, 
with the goal of establishing safe perioperative management procedures for elderly patients. This was done by conducting a retrospective survey of general anesthesia and postoperative management in elderly patients aged 75 years and above at our hospital.

\section{Material and Methods}

The medical protocol of this retrospective study followed the Declaration of Helsinki, and was conducted with the approval of the Institutional Research Board and Ethics Committee of the Graduate School of Dentistry, Kanagawa Dental University (Approval Number 404). The subjects were patients aged 75 years and above who underwent general anesthesia for oral and maxillofacial surgery at Kanagawa Dental University Hospital during the two years from April 2015 to March 2017.

This study retrospectively reviewed patient medical, anesthesia, and nursing records to examine the items listed below. Evaluation parameters included patient characteristics (age, sex, height, body weight), dental diagnosis, details of surgery, concomitant systemic diseases, preoperative laboratory test results, general anesthesia techniques (induction and maintenance), changes in intraoperative vital signs, number of days in the hospital, anesthesia duration, surgery duration, type of perioperative comorbidities, anesthetic dose during induction, use of hemodynamic agents, and changes in cognitive function and abnormal behavior after surgery. Patients preoperatively diagnosed with dementia by a specialist were classified as 'having a diagnosis of dementia'. The extent of dementia was evaluated preoperatively using the Clinical Dementia Rating scale [18], based on diagnosis by a specialist and interviews with caregivers about the patient's daily life. Based on the review results, patients with and without POD and abnormal behavior were compared to identify factors related to POD. POD and abnormal behavior was defined as the onset of abnormal speech and behavior during the postoperative period, that lasted for some time from just after the operation up to about the 14 th postoperative day.

Statistical analysis was performed using SPSS version 16.0 software (SPSS Japan, Tokyo, Japan). The data are expressed as median values (interquartile range). The Mann-Whitney U test was used for statistical analysis. Logistic regression analysis was used to analyze factors associated with POD and abnormal behavior. A significance level of $p<0.05$ was set for each test.

\section{Results}

Patient backgrounds are shown in Table 1. Forty-two patients, 15 men and 27 women, with a median age of 81 years and highest age of 94 years were enrolled. A total of 46 cases were analyzed, including 2 surgeries each in 4 patients. The dental diagnoses in these patients were malignant tumor (16 cases), osteomyelitis of the jaw (10 cases), cyst ( 8 cases), benign tumor ( 9 cases), fracture of the jaw ( 2 cases), and periimplantitis ( 1 case). The median duration of surgery was 79 min (range: 20-363 min), and no major surgeries, including reconstruction surgeries, were performed. The comorbidities were brain and nervous system disorders in 13 cases (cerebral infarction, 5 cases; dementia, 7 cases; other, 1 case), respiratory disorders in 4 cases (pulmonary emphysema, 4 cases), cardiovascular disorders in 35 cases (hypertension, 28 cases; ischemic heart disease, 6 cases; other, 1 case), metabolic disorders in 12 cases (diabetes, 7 cases; dyslipidemia, 7 cases, and other conditions in 29 cases. Dementia was diagnosed preoperatively in 6 patients ( 7 cases).

Table 1. Patient's characteristics.

\begin{tabular}{|c|c|}
\hline Patient & 42 patients ( 46 cases) \\
\hline Age (y) & $81(77-86)$ \\
\hline Sex (male/female) & $15 / 27$ patients ( $17 / 29$ cases $)$ \\
\hline Height (cm) & $154(148.8-162.3)$ \\
\hline Weight (kg) & $50.9(43.8-57.0)$ \\
\hline Number of complications $(1 / 2 / 3 / 4 / 5 / 6)$ & $4 / 12 / 11 / 10 / 7 / 2$ \\
\hline Preoperative diagnosis of dementia (yes/no) & $6 / 36$ patients $(7 / 39$ cases $)$ \\
\hline Number of days in hospital (days) & $13.5(6.3-19.8)$ \\
\hline Anesthesia time (min) & $155(110-253.8)$ \\
\hline Operation time (min) & $79(58.8-175.3)$ \\
\hline Blood loss (mL) & $25.5(5-100)$ \\
\hline Urine output (mL) & $165(100-405)$ \\
\hline $\begin{array}{l}\text { Induction of anesthesia (rapid/slow/awake } \\
\text { intubation) }\end{array}$ & $30 / 8 / 8$ \\
\hline $\begin{array}{l}\text { Maintenance of anesthesia (AOS+R/GOS } \\
+\mathrm{F} / \mathrm{AOD}+\mathrm{R})\end{array}$ & $24 / 16 / 6$ \\
\hline \multicolumn{2}{|c|}{$\begin{array}{l}\text { A: Air; G: Nitrous oxide; O: Oxygen; S: Sevoflurane; D: Desflurane; F: Fentanyl } \\
\text { R: Remifentanil }\end{array}$} \\
\hline The data are expressed as median values (inter & rquartile range). \\
\hline
\end{tabular}

The factors associated with POD and abnormal behavior are shown in Table 2. There were no significant differences in the postoperative occurrence of delirium and abnormal behavior in relation to sex, height, body weight, number of concomitant diseases, number of days in hospital, surgery duration, blood loss, urine volume, propofol dose at induction, fentanyl dose at induction, lowest systolic blood pressure at induction and during anesthesia, use of vasopressors and antihypertensive agents, preoperative red blood cell count, hemoglobin level, and total protein level (Table 2). However, a preoperative diagnosis of dementia $(\mathrm{P}<0.001)$, age $(\mathrm{P}=0.009)$ and anesthesia duration $(\mathrm{P}=0.048)$ were significantly associated with the postoperative occurrence of delirium and abnormal behavior. A statistically significant difference in propofol dose at induction, and induction and maintenance techniques were present in patients with and without POD and abnormal behavior, although the differences were related to the anesthesiologists' decisions regarding reduction in the volume of propofol or choice about slow induction or awake intubation in order to avoid a decrease in blood pressure. Since these findings were 
not the objectives of this study, they were not considered significant. Logistic regression analysis was performed with POD and abnormal behavior as dependent variables, and preoperative diagnosis of dementia, age and anesthesia duration as independent variables. Analysis identified 'having a diagnosis of dementia before surgery' as a factor associated with $\mathrm{POD}$ and abnormal behavior $(\mathrm{P}=0.014$, odds ratio: 456.6, 95\% confidence interval: 3.48-59997.47) (Table 3).

Table 2. Occurrence of postoperative delirium and abnormal behavior

\begin{tabular}{|c|c|c|c|}
\hline & \multicolumn{2}{|c|}{ Postoperative delirium and abnormal behavior } & \multirow[t]{2}{*}{$P$ value } \\
\hline & negative $(n=40)$ & positive $(n=6)$ & \\
\hline Age $(y)$ & $80(77-85)$ & $87(85-89)$ & 0.009 \\
\hline Sex (male/female) & $15 / 25$ & $2 / 4$ & 0.845 \\
\hline Height (cm) & $154(148.3-162)$ & $152(147.5-167)$ & 0.806 \\
\hline Weight (kg) & $51(46.3-57.0)$ & $40(37.3-65.7)$ & 0.327 \\
\hline Number of complications $(1 / 2 / 3 / 4 / 5 / 6)$ & $4 / 10 / 10 / 7 / 6 / 2$ & $0 / 2 / 1 / 3 / 1 / 0$ & 0.689 \\
\hline Preoperative diagnosis of dementia (yes/no) & $2 / 38$ & $5 / 1$ & $<0.001$ \\
\hline Number of days in hospital (days) & $12.5(5.8-19.3)$ & $15(5.5-76.3)$ & 0.523 \\
\hline Anesthesia duration (min) & $147.5(109.3-238.8)$ & $290.5(156.3-367.5)$ & 0.048 \\
\hline Operation duration (min) & $74(56.3-168.3)$ & $181.5(63.3-263.3)$ & 0.166 \\
\hline Blood loss (mL) & $20.5(5-95)$ & $64.5(15.8-212.5)$ & 0.325 \\
\hline Urine output (mL) & $150(92.5-370)$ & $235(175-550)$ & 0.116 \\
\hline Volume of propofol at induction (mg) & $60(50-60)$ & $20(0-40)$ & 0.027 \\
\hline Volume of fentanyl at induction $(\mu \mathrm{g})$ & $50(50-100)$ & $75(47.5-100)$ & 0.786 \\
\hline Induction of anesthesia (rapid/slow/awake intubation) & $29 / 7 / 4$ & $1 / 1 / 4$ & 0.002 \\
\hline Maintenance of anesthesia $(A O S+R / G O S+F / A O D+R)$ & $23 / 13 / 4$ & $1 / 3 / 2$ & 0.043 \\
\hline Minimum SBP at induction $(\mathrm{mmHg})$ & $110(95.8-120)$ & $115(96.3-146.3)$ & 0.49 \\
\hline Minimum SBP during anesthesia $(\mathrm{mmHg})$ & $80(70-90)$ & $82.5(80-100)$ & 0.32 \\
\hline Use of pressor agent (yes/no) & $30 / 10$ & $3 / 3$ & 1 \\
\hline Use of antihypertensive drug (yes/no) & $9 / 31$ & $1 / 5$ & 1 \\
\hline Preoperative red blood cell $\left(\times 10^{4} / \mathrm{mm}^{3}\right)$ & $395(369.5-419.8)$ & $370(350.8-411.5)$ & 0.267 \\
\hline Preoperative hemoglobin (g/dL) & $12.1(11.6-13.4)$ & $11.6(11.0-12.6)$ & 0.203 \\
\hline Preoperative total protein (g/dL) & $7.2(6.9-7.4)$ & $7.0(6.5-7.5)$ & 0.607 \\
\hline
\end{tabular}

A: Air; G: Nitrous oxide; O: Oxygen; S: Sevoflurane; D: Desflurane; F: Fentanyl; R: Remifentanil; SBP: Systolic Blood Pressure

The data are expressed as median values (interquartile range).

Table 3. Logistic regression analysis.

\begin{tabular}{|c|c|c|c|}
\hline & $P$ value & Odds ratio & $95 \% \mathrm{Cl}$ \\
\hline $\begin{array}{l}\text { Preoperative diagnosis of } \\
\text { dementia }\end{array}$ & 0.014 & 456.6 & $3.48-59997.47$ \\
\hline Age & 0.063 & 1.544 & $0.977-2.439$ \\
\hline Anesthesia duration & 0.903 & 1.001 & $0.990-1.011$ \\
\hline
\end{tabular}

Patients with POD and abnormal behavior are listed in Table 4. Dementia was diagnosed before surgery in Cases 1, 2, 3, 5, 6, and 7 (6 patients, 7 cases). Case 4 was not diagnosed with dementia before surgery, but from postoperative day 7 until discharge on day 16 , the patient was unable to remember his doctor's name or the fact that he had undergone surgery, and continued pressing the nurse's call button and saying repeatedly "I'm going home, I'm going home". Cases 2, 3, and 6 exhibited cardinal symptoms of dementia from before surgery, and removed their gastric tubes several hours after surgery. Case 3 wandered outside the hospital on postoperative day one. Overall, the behavioral symptoms occurred from a few hours after surgery until the day after surgery in four of these cases; two of them had behavioral symptoms for longer durations. 


\section{Discussion}

Our survey of POD and abnormal behavior in elderly patients aged 75 years and above found that these complications were more common in patients with a preoperative diagnosis of dementia, higher age and in patients with a long duration of anesthesia. Preoperative diagnosis of dementia, in particular, was a factor strongly linked to POD and abnormal behavior. The proportion of elderly people in Japan is increasing, with 16.46 million people aged 75 years and over in 2015, accounting for $13.0 \%$ of the total population [19]. Our department has extensive experience in the perioperative management, including general anesthesia management, of elderly patients, and we consider cautious perioperative management to be essential, given the physiological changes and multiple comorbidities associated with aging. POD and POCD have become growing problems in recent years, and there appear to be many contributing factors [1-3]

Table 4. Case presentation with pre- and postoperative cognitive impairment.

\begin{tabular}{|c|c|c|c|c|c|c|c|c|c|c|c|c|c|}
\hline $\begin{array}{l}\text { Cas } \\
\text { e }\end{array}$ & Sex & $\begin{array}{l}\text { Age } \\
\text { (yr) }\end{array}$ & $\begin{array}{l}\text { Preop. } \\
\text { diag. of } \\
\text { dementia }\end{array}$ & ADL & $\begin{array}{l}\text { AS } \\
\text { A- } \\
\text { PS }\end{array}$ & $\begin{array}{l}\text { OP } \\
\text { time } \\
(\min )\end{array}$ & $\begin{array}{l}\text { Anest } \\
\text { h time } \\
\text { (min) }\end{array}$ & Induction (drugs) & $\begin{array}{l}\text { Mainte } \\
\text { nance }\end{array}$ & $\begin{array}{l}\text { Bloo } \\
\text { d } \\
\text { loss } \\
(\mathrm{mL})\end{array}$ & $\begin{array}{l}\text { Urine } \\
\text { outp } \\
\text { ut } \\
(\mathrm{mL})\end{array}$ & $\begin{array}{l}\text { Complication } \\
\text { during anesth. } \\
\text { (treatment) }\end{array}$ & $\begin{array}{l}\text { Day of postoperative } \\
\text { delirium r and } \\
\text { abnormal behavior } \\
\text { and contents }\end{array}$ \\
\hline 1 & M & 77 & $\begin{array}{l}\text { frontotemp } \\
\text { oral (mild) }\end{array}$ & $\begin{array}{l}\text { walk } \\
\text { by } \\
\text { himself }\end{array}$ & 2 & 37 & 92 & Rapid (P 70 mg+F $50 \mu \mathrm{g})$ & GOS $+F$ & 10 & 0 & $\begin{array}{l}\text { BP decrease } \\
\text { (ephedrine) }\end{array}$ & none \\
\hline 2 & $\mathrm{~F}$ & 89 & $\begin{array}{l}\text { Alzheimer } \\
\text { (severe) }\end{array}$ & $\begin{array}{l}\text { wheel } \\
\text { chair }\end{array}$ & 2 & 135 & 250 & $\begin{array}{l}\text { Awake intubation (M } 1 \mathrm{mg}+\mathrm{F} \\
50 \mu \mathrm{g})\end{array}$ & $\mathrm{GOS}+\mathrm{F}$ & 70 & 100 & $\begin{array}{l}\text { BP decrease } \\
\text { (ephedrine) }\end{array}$ & $\begin{array}{l}0,2,5 \text { POD: removal of } \\
\text { GT cardinal symptoms } \\
\text { (severe) })^{*}\end{array}$ \\
\hline 3 & $\mathrm{~F}$ & 86 & $\begin{array}{l}\text { Dementia } \\
\text { (severe) }\end{array}$ & roam & 2 & 70 & 170 & $\begin{array}{l}\text { Awake intubation (M } 1 \mathrm{mg}+\mathrm{F} \\
50 \mu \mathrm{g} \text { ) (MAC GRATH was } \\
\text { used because of difficult } \\
\text { intubation) }\end{array}$ & GOS+F & 20 & 550 & $\begin{array}{l}\text { BP decrease } \\
\text { (nicardipine) } \\
\text { PVC }\end{array}$ & $\begin{array}{l}2 \mathrm{~h} \text { after OP: removal of } \\
\mathrm{GT} 1 \mathrm{POD} \text { : roaming } \\
\text { cardinal } \\
\begin{array}{lr}\text { (severe) } & \text { symptoms }\end{array}\end{array}$ \\
\hline 4 & M & 88 & none & $\begin{array}{l}\text { walk } \\
\text { by } \\
\text { himself }\end{array}$ & 2 & 220 & 331 & $\begin{array}{l}\text { Awake intubation (M } 1 \mathrm{mg}+\mathrm{F} \\
100 \mu \mathrm{g})\end{array}$ & $A O S+R$ & 59 & 550 & $\begin{array}{l}\text { BP decrease } \\
\text { (ephedrine) }\end{array}$ & $\begin{array}{l}\text { 7-16 POD: disturbance } \\
\text { of orientation and } \\
\text { memory }\end{array}$ \\
\hline 5 & M & 89 & $\begin{array}{l}\text { Alzheimer } \\
\text { (mild) }\end{array}$ & $\begin{array}{l}\text { walk } \\
\text { by } \\
\text { himself }\end{array}$ & 2 & 43 & 115 & $\begin{array}{l}\text { Awake intubation (M } 2 \mathrm{mg}+\mathrm{F} \\
100 \mu \mathrm{g})\end{array}$ & GOS $+F$ & 3 & 250 & None & $\begin{array}{l}0-3 \quad h \text { after OP: } \\
\text { excitement }\end{array}$ \\
\hline 6.1 & $\mathrm{~F}$ & 85 & $\begin{array}{l}\text { Dementia } \\
\text { (moderate) }\end{array}$ & $\begin{array}{l}\text { wheel } \\
\text { chair }\end{array}$ & 2 & 363 & 455 & Rapid (P 40 mg+F $50 \mu \mathrm{g})$ & $A O D+R$ & 430 & 220 & $\begin{array}{l}\text { BP decrease } \\
\text { (ephedrine) }\end{array}$ & $\begin{array}{l}9 \mathrm{~h} \text { after OP-1 POD: } \\
\text { removal of GT cardinal } \\
\text { symptoms (moderate) }\end{array}$ \\
\hline 6.2 & $\mathrm{~F}$ & 85 & $\begin{array}{l}\text { Dementia } \\
\text { (moderate) }\end{array}$ & $\begin{array}{l}\text { wheel } \\
\text { chair }\end{array}$ & 2 & 230 & 335 & Slow $(\mathrm{OS}+\mathrm{F} 50 \mu \mathrm{g})$ & $A O D+R$ & 140 & 200 & PAC & $\begin{array}{l}\text { Cardinal symptoms } \\
\text { (moderate) }\end{array}$ \\
\hline 7 & M & 80 & $\begin{array}{l}\text { Dementia } \\
\text { (mild) }\end{array}$ & $\begin{array}{l}\text { walk } \\
\text { by } \\
\text { himself }\end{array}$ & 2 & 465 & 620 & Slow (OS+F $200 \mu \mathrm{g})$ & $A O S+R$ & 200 & 100 & None & None \\
\hline
\end{tabular}

*The patient demonstrated as the same level of core symptoms as preoperatively. P: Propofol; F: Fentanyl; M: Midazolam; G: Nitrous Oxide; O: Oxygen; S: Sevoflurane; R: Remifentanil; PAC: Premature Atrial Contraction; PVC: Premature Ventricular Contraction; OP: Operation; POD: Postoperative Day; GT: Gastric Tube; h: Hours

Table 5 compares POD and POCD. POD is a psychiatric syndrome that has an acute onset, causes disturbances of consciousness, attention, perception and cognitive function, and shows diurnal variation. It occurs in $9 \%$ of non-cardiac surgery patients and $44 \%$ of patients admitted to the ICU after surgery, and is associated with increased postoperative mortality and incidence of complications, longer hospital stays, increased medical costs, and delayed recovery of function $[1,2,20]$. POD is categorized as hyperactive, hypoactive, and mixed types, and can be caused by neurotransmitter abnormalities, systemic inflammatory responses (elevated serum interleukin-6 (IL-6) and IL-8) spreading to the brain, stress responses (elevated serum cortisol), sleep disturbances, drugs, dehydration, and abnormal electrolyte and glucose levels [21].
POCD involves postoperative higher brain dysfunction encompassing impairment of memory, attention, and executive function, and can persist from a few weeks to a few months after surgery $[1,2,20]$. After non-cardiac surgery, POCD is seen in elderly patients aged 60 years and over at a rate of $25.8 \%$ after one week, and $9.9 \%$ after 3 months, but in patients aged 59 years and below, the respective rates are only $3.4 \%$ and $2.8 \%$ [4]. Even after minor surgery, POCD is seen in $6.8 \%$ of patients after one week, and in elderly patients aged 75 years and above the incidence is higher for inpatient surgery $(18 \%)$ than outpatient surgery $(0 \%)$, with a similar trend seen after 3 months [22]. The incidence of POCD is, thus, higher in elderly patients than younger patients, even higher in elderly patients admitted to the hospital, and higher still after major invasive surgery. Patients with POCD one week after surgery have difficulty working, and those with POCD after 3 months have 
higher mortality [4]. As with POD, the cause is thought to be a systemic inflammatory response (elevated serum IL-6, high mobility group box 1 (HMGB1), IL-1 $\beta$, or tumor necrosis factor $\alpha(\mathrm{TNF} \alpha)$ ) spreading to the brain [21]. Although many risk factors have been reported for both complications, the factors that matched our study observations were patients with cognitive impairment before surgery and a long duration of anesthesia or surgery $[2,4,5]$. In none of the other patients, surgery, or anesthesia-related factors were associated with the occurrence of POD and POCD.

Table 5. The feature of $P O D$ and $P O C D$.

\begin{tabular}{|c|c|c|}
\hline & POD & POCD \\
\hline Onset of symptoms & $\begin{array}{l}\text { from several hours to } \\
\text { several days }\end{array}$ & $\begin{array}{l}\text { from several weeks to } \\
\text { several months }\end{array}$ \\
\hline Critical form of onset & acute & subtle \\
\hline Duration of symptoms & $\begin{array}{l}\text { from several days to several } \\
\text { weeks }\end{array}$ & $\begin{array}{l}\text { from several weeks to } \\
\text { several months }\end{array}$ \\
\hline Attention & impaired & impaired \\
\hline Consciousness & altered & normal \\
\hline Reversibility & usually & $\begin{array}{l}\text { usually, but can be long } \\
\text { lasting }\end{array}$ \\
\hline
\end{tabular}

POD: Postoperative Delirium; POCD: Postoperative Cognitive Dysfunction. (Note: adapted from reference 2 with modification)

With regard to the relationship between Alzheimer's disease and anesthetic agents, in vivo studies using mice and rats have shown that exposure to volatile anesthetic agents produced more severe pathological changes of Alzheimer's disease (increased deposits of amyloid $\beta$-protein, enhanced phosphorylation of tau protein, nerve cell death, etc.) $[6,7]$, whereas in vitro studies using cultured nerve cells found that the intravenous anesthetic agents propofol and thiopental did not worsen the pathological changes [8]. In clinical practice, there are no differences in the incidence of POD and POCD between surgery under general anesthesia and under local anesthesia $[9,10]$, anesthesia with a volatile anesthetic (xenon) and anesthesia with propofol [11], and anesthesia with the volatile anesthetics sevoflurane and desflurane [12]. On the other hand, recovery of postoperative cognitive function is faster following desflurane than sevoflurane anesthesia [23]. Also, there are significantly more cases of POCD with isoflurane than with desflurane [13]. There has been a mix of contradictory reports on the effects of anesthetics on POD and POCD, including basic research, but no consistent trends can be seen. Our study similarly found no significant differences in terms of the techniques used for anesthesia induction and maintenance.

Several reports suggested some risk factors for POD in patients undergoing major head and neck cancer surgery, with older age, male gender, history of psychiatric disorders, American Society of Anesthesiologists physical status grade III and above, longer duration of surgery $(>9-10 \mathrm{~h})$, intraoperative massive hemorrhage with blood transfusions, flap reconstruction and neck dissection, and duration of ICU stay being identified as significant risk factors [14-17]. Some of these factors (preoperative diagnosis of dementia, higher age and long duration of anesthesia) are similar to our results, indicating that they may also be risk factors for POD in patients undergoing non-major oral and maxillofacial surgery.

The results of this study are consistent with reports that cerebral dysfunction, including known cognitive impairment, in non-ICU patients is a risk factor for delirium $[1,5]$. However, there were no associations between POD/POCD and general risk factors, such as hypoxemia, decreased cerebral perfusion due to decreased blood pressure, and anesthesia methods related to these events. One study reported that POCD can be reduced by preventing decreases in cerebral blood flow by managing blood pressure, appropriate maintenance of blood oxygen and partial pressure of carbon dioxide, and appropriate maintenance of anesthesia depth (BIS 40-60) [24]. Another study reported that by maintaining BIS at 40-60, the volume of anesthetic used during surgery was reduced and the incidence of POCD 3 months after surgery was lower, suggesting that POCD could be inhibited by controlling the amounts of general anesthetics used [25]. In our study, there was no statistically significant difference in the occurrence of POD in terms of anesthetic dose, since this was determined by the anesthesiologists' attempts to avoid a decrease in blood pressure during anesthesia induction and maintenance by using slow induction or awake intubation, or by using a lower volume of anesthetics. It is, therefore, important that these factors are taken into account in anesthesia management. In Case 4, who was not diagnosed with dementia before surgery and displayed cognitive impairment from postoperative day 7 , the change in environment entailed by the hospital stay was the most likely cause of cognitive impairment, rather than the surgery or anesthesia.

Since this was a retrospective study based on medical and nursing records, a limitation of this study was that although the abnormal behavior and impairment of memory and orientation seen in POD could be captured by the survey, impaired judgment and problem-solving ability seen in POCD patients could not. As a result, this study did not fully evaluate postoperative cognitive impairment and may not have been able to adequately detect patients with POCD. Preoperative mild cognitive impairment is also a risk factor for POD and POCD [26]. Therefore, for patients with mild to moderate dementia before surgery in particular, there is a need for a larger-scale, prospective registry study using the Mini-Mental State Examination to evaluate patients before and after surgery.

\section{Conclusion}

We conducted a retrospective survey of general anesthesia and postoperative management in elderly patients aged 75 years and above undergoing non-major oral and maxillofacial surgery, to identify the factors associated with POD and abnormal behavior. We found that these complications were more common in patients with a preoperative diagnosis of dementia higher age and in patients with a longer duration of 
anesthesia. Preoperative diagnosis of dementia, in particular, was a factor strongly linked to POD and abnormal behavior.

\section{Acknowledgment}

This study was supported by departmental funding.

\section{References}

1. Deiner S, Silverstein JH. Postoperative delirium and cognitive dysfunction. Br J Anaesth 2009; 103: i41-i46.

2. Krenk L, Rasmussen LS. Postoperative delirium and postoperative cognitive dysfunction in the elderly- what are the differences? Minerva Anesthesiol 2011; 77: 742-749.

3. Coburn M, Fahlenkamp A, Zoremba N, Schaelte G. Postoperative cognitive dysfunction: Incidence and prophylaxis. Anesthesist 2010; 59: 177-184.

4. Moller JT, Cluitmans P, Rasmussen LS, Houx P, Rasmussen H, Canet J, Rabbitt P, Jolles J, Larsen K, Hanning CD, Langeron O, Johnson $T$, Lauven PM, Kristensen PA, Biedler A, van Beem H, Fraidakis O, Silverstein JH, Beneken JE, Gravenstein JS. Long-term postoperative cognitive dysfunction in the elderly ISPOCDI study. ISPOCDI investigators. International Study of PostOperatove Cognitive Dysfunction. Lancet 1998; 351: 857-861.

5. Silverstein JH, Deiner SG. Perioperative delirium and its relationship to dementia. Prog Neuropsychopharmacol Biol Psychiatry 2013; 3: 108-115.

6. Dong Y, Zhang G, Zhang B, Moir RD, Xia W, Marcantonio ER, Culley DJ, Crosby G, Tanzi RE, Xie Z. The common inhalational anesthetic sevoflurane induces apoptosis and increases beta-amyloid protein levels. Arch Neurol 2009; 66: 620-630.

7. Callaway JK, Jones NC, Royse AG, Royse CF. Sevoflurane anesthesia does not impair acquisition learning or memory in the morris water maze in young adult and aged rats. Anesthesiology 2012; 117: 1091-1101.

8. Yamamoto N, Arima H, Sugiura T, Hirate H, Taniura H, Suzuki K, Sobue K. Propofol and Thiopental suppress amyloid Fibril and GMI ganglioside expression through the $\gamma$-aminobutyric acid A receptor. Anesthesiology 2013; 118: 1408-1416.

9. O’Dwyer PJ, Serpell MG, Millar K, Paterson C, Young D, Hair A. Local or general anesthesia for open hernia repair: a randomized trial. Ann Surg 2003; 237: 574-579.

10. Rasmussen LS, Johnson T, Kuipers HM, Kristensen D, Siersma VD, Vila P, Jolles J, Papaioannou A, Abildstrom H, Silverstein JH, Bonal JA, Raeder J, Nielsen IK, Korttila K, Munoz L, Dodds C, Hanning CD, Moller JT. ISPOCD2 (International Study of Postoperative Cognitive Dysfunction) Investigators. Does anesthesia cause postoperative cognitive dysfunction? a randomized study of regional versus general anesthesia in 438 elderly patients. Acta Anesth Scand 2003; 47: 260-266.

11. Höcker J, Stapelfeldt C, Leiendecker J, Meybohm P, Hanss R, Scholz J, Bein B. Postoperative neurocognitive dysfunction in elderly patients after xenon versus propofol anesthesia for major noncardiac surgery: a double-blinded randomized controlled pilot study. Anesthesiology 2009; 110: 1068-1076.

12. Rörtgen D, Kloos J, Fries M, Grottke O, Rex S, Rossaint R, Coburn M. Comparison of elderly cognitive function and recovery after desflurane or sevoflurane anesthesia in the elderly: a doble-blinded randomized controlled trial. $\mathrm{Br} \mathrm{J}$ Anaesth 2010; 104: 167-174.

13. Zhang B, Tian M, Zhen Y, Yue Y, Sherman J, Zheng H, Li S, Tanzi RE, Marcantonio ER, Xie Z. The effect of isoflurane and desflurane on cognitive function in humans. Anesth Analg 2012; 114: 410-415.

14. Yamagata K, Onizawa K, Yusa H, Wakatsuki T, Yanagawa T, Yoshida H. Risk factors for postoperative delirium in patients undergoing head and neck cancer surgery. Int J Oral Maxillofac Surg 2005; 34: 33-36.

15. Hasegawa T, Saito I, Takeda D, Iwata E, Yonezawa N, Kakei Y, Sakakibara A, Akashi M, Minamikawa T, Komori T. Risk factors associated with postoperative delirium after surgery for oral cancer. J Cranio-Maxillo-Fac Surg 2015; 43: 1094-1098.

16. Zhu Y, Wang G, Liu S, Zhou S, Lian Y, Zhang C, Yang W. Risk factors for postoperative delirium in patients undergoing major head and neck cancer surgery: a metaanalysis. Jpn J Clin Oncol 2017; 47: 505-511.

17. Choi NY, Kim EH, Baek CH, Sohn I, Yeon S, Chung MK. Development of a nomogram for predicting the probability of postoperative delirium in patients undergoing free flap reconstruction for head and neck cancer. Eur J Surg Oncol 2017; 43: 683-688.

18. Hughes CP, Berg L, Danziger WL, Coben LA, Martin RL. A new clinical scale for the staging of dementia. $\mathrm{Br} \mathrm{J}$ Psychiatry 1982; 140: 566-572.

19. http://www.mhlw.go.jp/seisakunitsuite/bunya/ hukushi_kaigo/kaigo_koureisha/chiiki-houkatsu/dl/ link1-1.pdf

20. Fong HK, Sands LP, Leung JM. The role of postoperative analgesia in delirium and cognitive decline in elderly patients: a systemic review. Anesth Analg 2006; 102: 1255-1266.

21. Riedel B, Browne K, Silbert B. Cerebral protection: inflammation, endothelial dysfynction, and postoperative cognitive dysfunction. Curr Opin Anaesthesiol 2014; 27 : 89-97.

22. Canet J, Raeder J, Rasmussen LS, Enlund M, Kuipers HM, Hanning CD, Jolles J, Korttila K, Siersma VD, Dodds C, Abildstrom H, Sneyd JR, Vila P, Johnson T, Muñoz Corsini L, Silverstein JH, Nielsen IK, Moller JT. ISPOCD2 investigators. Cognitive dysfunction after minor surgery in the elderly. Acta Anaesthesiol Scand 2002; 47: 1204-1210.

23. Tachibana S, Hayase T, Osuda M, Kazuma S, Yanakage M. Recovery of postoperative cognitive function in elderly patients after a long duration of desflurane anesthesia: a pilot study. J Anesth 2015; 29: 627-630. 
24. Ballard C, Jones E, Gauge N, Aarsland D, Nilsen OB, Saxby BK, Lowery D, Corbett A, Wesnes K, Katsaiti E, Arden J, Amoako D, Prophet N, Purushothaman B, Green D. Optimised anesthesia to reduce postoperative cognitive decline (POCD) in older patients undergoing elective surgery, a randomized controlled trial. PLoS One 2012; 7 : e37410.

25. Chan MT, Cheng BC, Lee TM, Gin T. CODA Trial Group. BIS-guided anesthesia decreases postoperative delirium and cognitive decline. J Neurosurg Anesthesiol 2013; 25: 33-42.

26. Crosby G, Culley DJ. Surgery and anesthesia: healing the body but harming the brain? Anesth Analg 2006; 112: 999-1001.

\section{*Correspondence to}

Yoshinari Morimoto

Department of Critical Care Medicine and Dentistry

Graduate School of Dentistry

Kanagawa Dental University

Japan 